\title{
New results in 3D-mesomechanical coupled analysis of external sulphate attack in concrete.
}

\author{
C. Biscaro ${ }^{* 1}$, A. Martinez ${ }^{\dagger}$, A. Pérez ${ }^{\dagger}$, C.M. López ${ }^{\dagger}$, G. Xotta ${ }^{1}$ and I. Carol ${ }^{\dagger}$ \\ ${ }^{1}$ Department of Civil, Environmental and Architectural Engineering \\ Università degli Studi di Padova \\ Via Marzolo, 9 - 35131 Padova, Italia \\ e-mail: caterina.biscaro@phd.unipd.it,giovanna.xotta@unipd.it \\ web page: https://www.unipd.it/en/icea \\ $\dagger$ Department of Civil and Environmental Engineering \\ Universidad Politècnica de Cataluña \\ Jordi Girona 1, Edif D2, E-08034 Barcelona, Spain \\ e-mail: ariadna.martinez.e@upc.edu, adria.perez@upc.edu, carlos.maria.lopez@upc.edu, \\ ignacio.carol@upc.edu
}

\begin{abstract}
External Sulphate Attack (ESA) is one of the main degradation processes affecting concrete structures. It takes place when the concrete is in an environment rich in sulphate ions and with a high humidity index. Once it has penetrated the concrete, sulphate undergoes chemical reactions that lead to the precipitation of expansive ettringite crystals that cause volumetric expansions of the cement paste/mortar, eventually leading to cracking and damage.

The FE analysis is undertaken by representing concrete as composed by aggregate pieces inserted in a cement/mortar matrix. Zero-thickness interface elements are pre-inserted to represent potential fractures along all aggregate-matrix as well as along some selected matrix-matrix element contacts. A fracture-based non-linear constitutive law proposed by Carol et al. [1] and later developed by Caballero et al. [2] is used for the interface elements. Concerning the reactive transport problem, the model follows the initial work by Tixier and Mobasher [3], which was introduced in a mesomechanical analysis with interfaces by Idiart et al. [4] in 2D, and later in 3D (but no coupling) by Pérez et al [5]. In the present paper, the effects of the coupling between mechanical and diffusion/reaction in 3D, due to the cubic law of the interface diffusivity, are demonstrated. The new results obtained confirm that, also in 3D, penetration of ions, expansive reactions as well as subsequent cracking and degradation, all take place much faster when the coupling effect due to the open interfaces is introduced.
\end{abstract}

\section{REFERENCES}

[1] I. Carol, P.C. Prat and C.M. López, "Normal/shear cracking model: application to discrete crack analysis", Journal of Engineering Mechanics, 123, 765-773 (1997).

[2] A. Caballero, I. Carol and C.M. López, "A meso-level approach to the 3D numerical analysis of crackimg and fracture of concrete materials", Fatigue and Fracture of Engineering Materials and Structures, 20, 979-991 (2006).

[3] R. Tixier and B. Mobasher, "Modeling of damage in cement-based materials subjected to external sulphate attack. I: Formulation. II: Comparison with experiments.” ASCE J. Mat. Civil Engng., 15, 305-322 (2003).

[4] A. Idiart, C.M. López, and I. Carol, "Chemo-mechanical analysis of concrete cracking and degradetion due to sulphate attack: a meso-scale model." Cem. Concr. Compos., 33, 411- 423 (2011).

[5] A.Perez, C. Riera, C.M. López and I. Carol, "3D-Mesomechanical analysis of the external sulfate attack in concrete" proceedings of the XIV International Conference on Computational Plasticity: Fundamentals and Applications, (5-7September Barcelona, Spain), p. 276-287, (2017). 